\title{
Synthesis and Antitumor Activity of Erlotinib Derivatives Linked With 1,2,3-Triazole
}

\author{
Peng Deng ${ }^{1 \dagger}$, Ge Sun ${ }^{2 \dagger}$, Jie Zhao $^{3}$, Kaitai Yao ${ }^{2 *}$, Miaomiao Yuan ${ }^{4 *}$, Lizeng Peng ${ }^{1 *}$ and \\ Longfei Mao ${ }^{1 *}$
}

${ }^{1}$ Key Laboratory of Agro-Products Processing Technology of Shandong Province, Key Laboratory of Novel Food Resources Processing Ministry of Agriculture, Institute of Agro-Food Science and Technology Shandong Academy of Agricultural Sciences, Jinan, China, ${ }^{2}$ School of Basic Medical Sciences, Cancer Research Institute, Southern Medical University, Guangzhou, China, ${ }^{3}$ Henan Engineering Research Center of Chiral Hydroxyl Pharmaceutical, School of Chemistry and Chemical Engineering, Henan Normal University, Xinxiang, China, ${ }^{4}$ The Eighth Affiliated Hospital, Sun Yat-sen University, Shenzhen, China

\section{OPEN ACCESS}

Edited by: Junmin Zhang,

Lanzhou University, China

Reviewed by:

Vincent Kam Wai Wong,

Macau University of Science and

Technology, Macao SAR, China

Jianguo Fang,

Lanzhou University, China

*Correspondence:

Kaitai Yao

ktyao1931@163.com

Miaomiao Yuan

yuanmm2019@163.com

Lizeng Peng

15954128918@163.com

Longfei Mao

longfeimao1988@163.com

${ }^{t}$ These authors have contributed equally to this work

Specialty section:

This article was submitted to Pharmacology of Anti-Cancer Drugs,

a section of the journal

Frontiers in Pharmacology

Received: 12 October 2021

Accepted: 25 November 2021

Published: 17 January 2022

Citation:

Deng $P$, Sun G, Zhao J, Yao K,

Yuan M, Peng $L$ and Mao $L$ (2022)

Synthesis and Antitumor Activity of Erlotinib Derivatives Linked With 1,2,3-

Triazole.

Front. Pharmacol. 12:793905. doi: 10.3389/fphar.2021.793905
Cervical cancer is one of the most important cause of cancer-related death and presents a major public health problem in many countries. To search for more novel antitumor agents against cervical cancer, 14 erlotinib-linked 1,2,3-triazole compounds were designed, synthesized, and evaluated for their anti-tumor activity. The compounds were confirmed by ${ }^{1} \mathrm{H}$ NMR, ${ }^{13} \mathrm{C} \mathrm{NMR}$, and high-resolution mass spectra (HR MS). Antitumor activity assay results indicated that six of those compounds have remarkable inhibitory activity against human cervical cancer HeLa cells in vitro, among which compound $4 \mathrm{~m}$ was the most potent with $\mathrm{IC}_{50}$ of $3.79 \mu \mathrm{M}$, and compounds $4 \mathrm{k}, 4 \mathrm{i}, 4 \mathrm{l}$, $4 \mathrm{~d}$, and $4 \mathrm{n}$ also demonstrated remarkable antitumor activity with $\mathrm{IC}_{50}$ of $3.79,4.16,4.36$, 7.02 , and $8.21 \mu \mathrm{M}$. We found three of the most potent compounds $4 \mathrm{~d}, 4 \mathrm{k}$, and $4 \mathrm{l}$ induced potent apoptosis and cell cycle arrest in HeLa cells, and compounds $4 \mathrm{~d}$ and $4 \mathrm{I}$ significantly restrained the cell colony formation and showed moderate epidermal growth factor receptor (EGFR) inhibitory activity with $\mathrm{IC}_{50}$ of 13.01 and $1.76 \mu \mathrm{M}$. Therefore, these experiments indicate that these erlotinib-linked 1,2,3-triazole compounds are potential to act as effective anticancer agents against cervical cancer.

Keywords: EGFR, erlotinib, 1,2,3-triazole, HeLa, antitumor activity

\section{INTRODUCTION}

Among women, cervical cancer ranks fourth for both incidence (6.6\%) and mortality (7.5\%) and is one of the most important cause of cancer-related death (Bray et al., 2018). Even if human papilloma virus (HPV) vaccination were approved and early screening efforts have been made, cervical cancer still represents a major public health problem in many countries due to increased percentage of locoregional and distant recurrences in advanced-inoperable cervical cancer. Furthermore, recurrent cervical cancer is not amenable to radical treatment, and de novo metastatic disease are considered incurable with poor prognosis (Liontos et al., 2019; Hill 2020). Thus, new active anticancer agents and their optimal combinations treatment are desperately needed.

Epidermal growth factor receptor (EGFR) is a protein tyrosine kinase transmembrane receptor encoded by proto-oncogene HER-1 (Roskoski 2014) and is overexpressed in a variety of cancers such as breast, cervical, liver, and non-small cell lung cancers. Quinazoline-based EGFR kinase inhibitors 

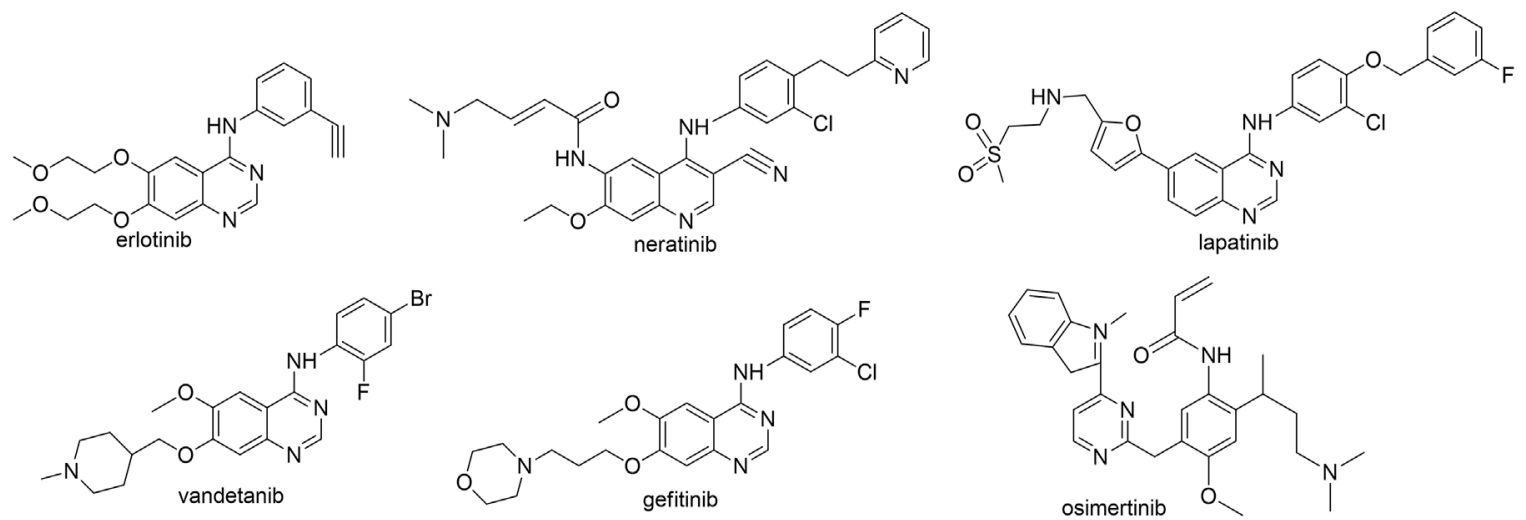

FIGURE 1 | The reported EGFR inhibitors.

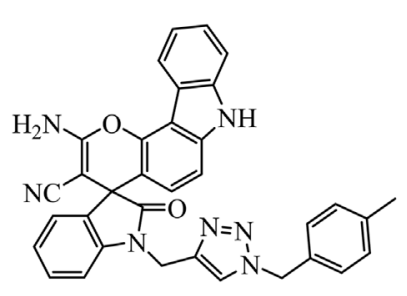

$6 \mathrm{~b}$

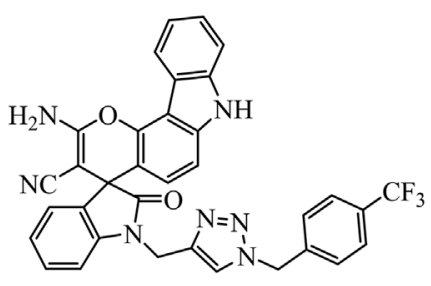

$6 \mathrm{~g}$

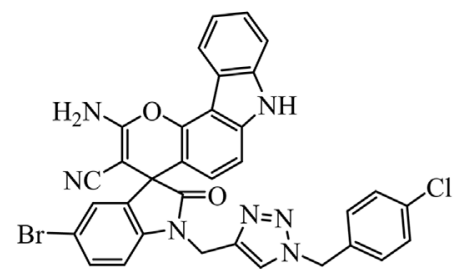

$6 s$

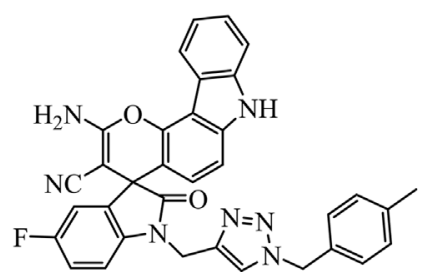

$6 u$<smiles>c1ccc(Cn2cc(COc3ccc(-c4nc5cc(C6=NCCN6)ccc5[nH]4)cc3)nn2)cc1</smiles>

$11 \mathrm{f}$<smiles>CC(C)NC(=N)c1ccc2[nH]c(-c3ccc(OCc4cn(Cc5ccc(Cl)cc5)nn4)cc3)nc2c1</smiles><smiles></smiles>

$17 \mathrm{~g}$

FIGURE 2 | The structures of compounds containing 1,2,3-triazole unit with anticancer activities against HeLa cells.

such as erlotinib (Schettino et al., 2008), neratinib, lapatinib (Tan et al., 2015), vandetanib (Yin et al., 2019), gefitinib (Cohen et al., 2003; Zhang et al., 2017), and osimertinib (Jänne et al., 2015; Qin et al., 2016) (Figure 1) are the major EGFR inhibitors used clinically. These EGFR kinase inhibitors and their derivates have been well studied and proved to be effective on various cancers including cervical cancer cells (Bhatia et al., 2020). Erlotinib is a classical EGFR inhibitor and was approved in 2003 for the treatment of advanced NSCLC that deteriorates after traditional chemotherapy (Mathew et al., 2015). Compared with traditional chemotherapy drugs, erlotinib improved the median survival rate from 4 months to more than 40 months and performs better in terms of progression-free survival rate, quality of life, and tolerability (Hirsch et al., 2017). 


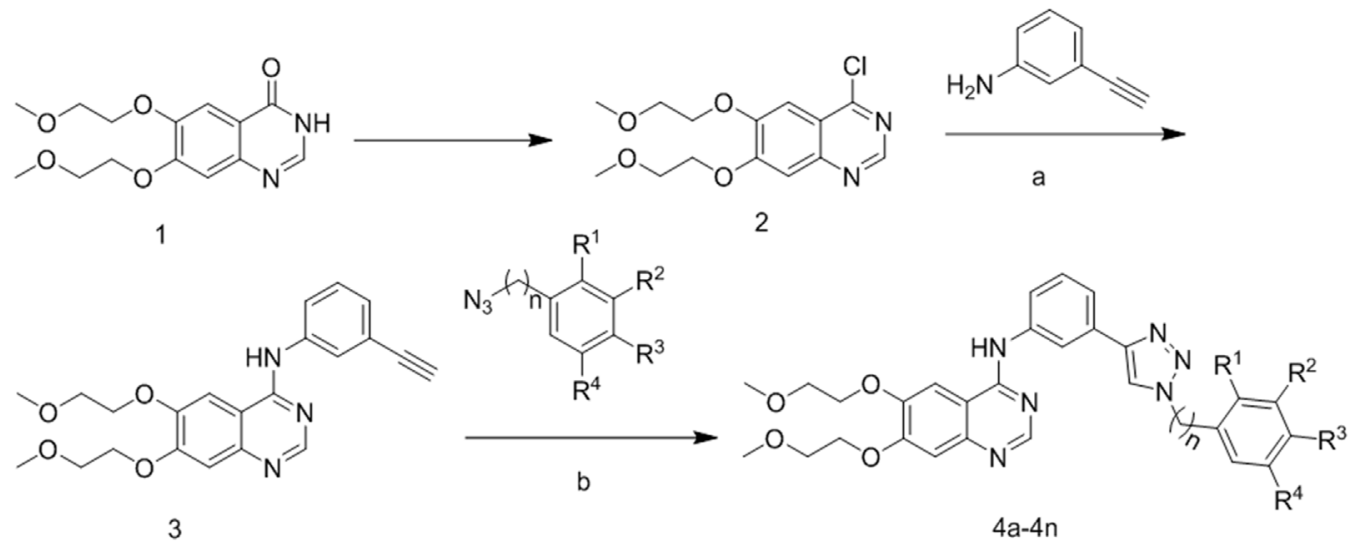

FIGURE 3 | Reagents and conditions. (A) $85^{\circ} \mathrm{C}$, isopropanol; (B) $60^{\circ} \mathrm{C}$, copper sulfate pentahydrate; sodium ascorbate.

1,2,3-Triazole is one of the important N-heterocyclic building blocks, and it plays a significant role in many compounds containing 1,2,3-triazole unit, which show good inhibitory effect against inflammation, cancer, and microbes (Mao L. et al., 2020). Moreover, CuAAC reaction (Safavi et al., 2018; Maddili et al., 2018; Saeedi et al., 2019), a convenient and regiospecific method of constructing 1,4-disubstituted triazoles (Thomopoulou et al., 2015), has aroused great interest and has been widely used in drug discovery (Hong et al., 2010). Our previous work revealed that compounds containing 1,2,3-triazole moiety exhibited good bioactivities such as antitumor or antibacterial activity (Mao LF. et al., 2020). In addition, a lot of studies demonstrated that compounds containing 1,2,3-triazole unit have potent anticancer activities against cervical cancer HeLa cells. In a study of Sarkar et al., a series of chromenocarbazole tethered 1,2,3-triazoles were designed and synthesized by Click chemistry based one-pot five-component reaction. Compounds $6 \mathrm{~b}, 6 \mathrm{~g}, 6 \mathrm{~s}$, and $6 \mathrm{u}$ showed excellent antiproliferative activity $\left(\mathrm{IC}_{50}=4.05,3.54,3.83\right.$, and $3.35 \mu \mathrm{M}$, respectively) in HeLa cells (Figure 2) (Chavan et al., 2019). In another study, Raic-Malic et al. synthesized a series of novel amidino 2-substituted benzimidazoles linked to 1,4-disubstituted 1,2,3-triazoles, and two of the new compounds $10 \mathrm{c}$ and $11 \mathrm{f}$ show potent antiproliferation activities against $\mathrm{HeLa}$ cells $\left(\mathrm{IC}_{50}=17.53\right.$ and $6.63 \mu \mathrm{M}$, respectively), which could be attributed to induction of apoptosis and primary necrosis. Besides, Chen et al. synthesized a series of 1-(benzofuran-3yl)-4-(3,4,5-trimethoxyphenyl)-1H-1,2,3-triazole derivatives and determined their antiproliferative activities against HCT116, HeLa, HepG2, and A549 cells, which could be associated with tubulin polymerization inhibitory activities. One of these compounds, 6-methoxy-N-phenyl-3-[4-(3,4,5-trimethoxyphenyl)1H-1,2,3-triazol-1-yl] benzofuran-2 carboxamide (17 g) exhibited potent antiproliferative activities against $\mathrm{HeLa}$ cells, with $\mathrm{IC}_{50}$ values of $0.73 \pm 0.67 \mu \mathrm{M}$ (Qi et al., 2020).

In order to search new molecules with antitumor activity, we substituted 1,2,3-triazole unit for alkynyl in the structure of erlotinib via CuAAC reaction to obtain fourteen 1,2,3-triazole derivatives that have never been reported in literatures, and their in vitro inhibition of HeLa cell activity were also screened.
TABLE 1 | Antitumor inhibitory activity of compounds $\mathbf{4 a - 4 n}$.

\begin{tabular}{|c|c|c|c|c|c|c|}
\hline \multirow[t]{2}{*}{ Compd no } & \multirow[t]{2}{*}{$n$} & \multirow[t]{2}{*}{ R1 } & \multirow[t]{2}{*}{$\mathbf{R} 2$} & \multirow[t]{2}{*}{ R3 } & \multirow[t]{2}{*}{ R4 } & \multirow{2}{*}{$\begin{array}{c}\mathrm{IC}_{50}(\boldsymbol{\mu} \mathrm{M}) \\
\text { HeLa }\end{array}$} \\
\hline & & & & & & \\
\hline $4 a$ & 1 & $\mathrm{H}$ & $\mathrm{H}$ & $\mathrm{H}$ & $\mathrm{H}$ & $>50$ \\
\hline $4 b$ & 1 & 1 & $\mathrm{H}$ & $\mathrm{H}$ & $\mathrm{H}$ & $11.50 \pm 1.69$ \\
\hline $4 c$ & 1 & $\mathrm{Br}$ & $\mathrm{H}$ & $\mathrm{H}$ & $\mathrm{H}$ & $21.31 \pm 7.79$ \\
\hline $4 d$ & 1 & $\mathbf{H}$ & $\mathrm{Br}$ & H & $\mathrm{Br}$ & $7.02 \pm 0.04$ \\
\hline $4 e$ & 1 & $\mathrm{H}$ & $\mathrm{OCH}_{3}$ & $\mathrm{H}$ & $\mathrm{H}$ & $>50$ \\
\hline $4 f$ & 0 & $\mathrm{~F}$ & $\mathrm{H}$ & $\mathrm{H}$ & $\mathrm{H}$ & $30.66 \pm 1.83$ \\
\hline $4 g$ & 0 & $\mathrm{H}$ & $\mathrm{H}$ & $\mathrm{F}$ & $\mathrm{H}$ & $9.05 \pm 0.53$ \\
\hline $4 \mathrm{~h}$ & 0 & $\mathrm{Cl}$ & $\mathrm{H}$ & $\mathrm{H}$ & $\mathrm{H}$ & $8.85 \pm 0.56$ \\
\hline $4 i$ & 0 & $\mathrm{Br}$ & $\mathrm{H}$ & $\mathrm{H}$ & $\mathrm{H}$ & $4.36 \pm 0.15$ \\
\hline $4 j$ & 0 & $\mathrm{H}$ & $\mathrm{H}$ & $\mathrm{Br}$ & $\mathrm{H}$ & $12.22 \pm 1.00$ \\
\hline $4 k$ & 0 & $\mathrm{OCH}_{3}$ & $\mathbf{H}$ & $\mathbf{H}$ & $\mathbf{H}$ & $4.16 \pm 0.48$ \\
\hline 41 & 0 & $\mathbf{H}$ & $\mathbf{H}$ & $\mathrm{CH}_{3}$ & $\mathbf{H}$ & $4.51 \pm 0.08$ \\
\hline $4 m$ & 0 & $\mathrm{H}$ & $\mathrm{NO}_{2}$ & $\mathrm{H}$ & $\mathrm{H}$ & $3.79 \pm 0.1$ \\
\hline $4 n$ & 0 & $\mathrm{H}$ & $\mathrm{OCH}_{2} \mathrm{CH}_{3}$ & $\mathrm{H}$ & $\mathrm{H}$ & $8.21 \pm 1.05$ \\
\hline Erlotinib & - & - & - & - & - & $39.50 \pm 3.34$ \\
\hline
\end{tabular}

${ }^{a} / C_{50}$, compound concentration required to inhibit tumor cell proliferation by $50 \%$ (mean $\pm S D, \mathrm{n}=3$ ).

IC50, (MM): 1-10 (very strong), 11-25 (strong), 26-50 (moderate), 51-100 (weak), above 100 (non-cytotoxic).

Bold values represents the compounds tested in the later part of this manuscript.

\section{CHEMISTRY}

The synthetic strategy for the preparation of the target compounds is illustrated in Figure 3. The chlorination of hydroxyl group from compound 1 with $\mathrm{SOCl}_{2}$ produced 4chloro-6,7-bis(2-methoxyethoxy) quinazoline (compound 2 ). Compound 2 reacted with 3 -ethynylaniline through nucleophile substitution reaction to produce erlotinib (compound 3). Copper(I)-catalyzed azide-alkyne cycloaddition between erlotinib and different azido compounds afforded the target compounds $4 \mathbf{a}-\mathbf{4 n}$. The reaction conditions of the steps were convenient and easy to control. The structures of some key intermediates and all target compounds were confirmed by nuclear magnetic resonance $\left({ }^{1} \mathrm{H}\right.$ NMR and ${ }^{13} \mathrm{C}$ NMR) and high-resolution mass spectrometry (HR MS). 
A

4d
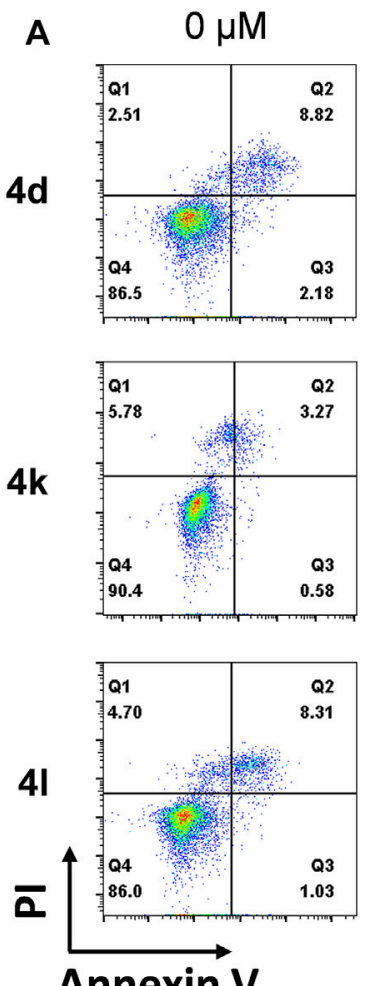

$3 \mu \mathrm{M}$
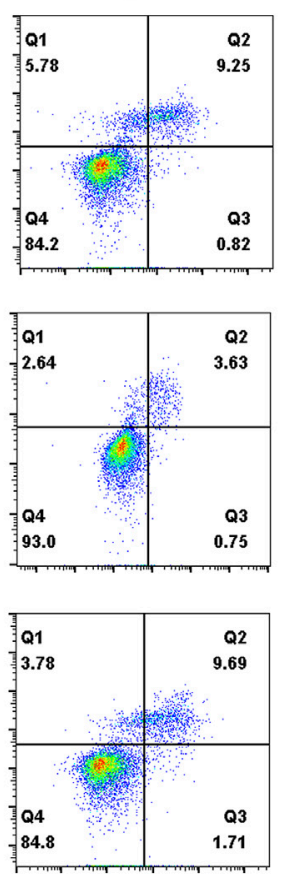

$6 \mu \mathrm{M}$
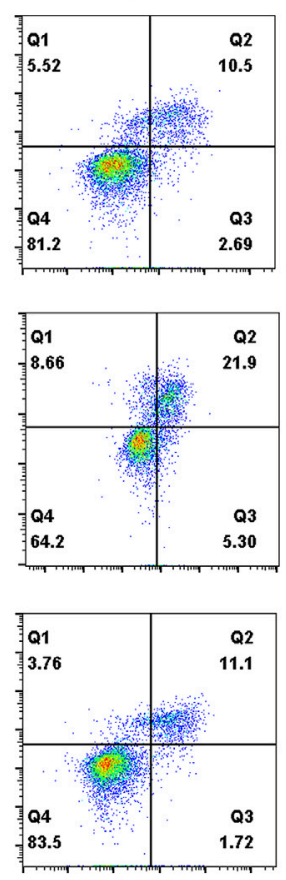

$12 \mu \mathrm{M}$
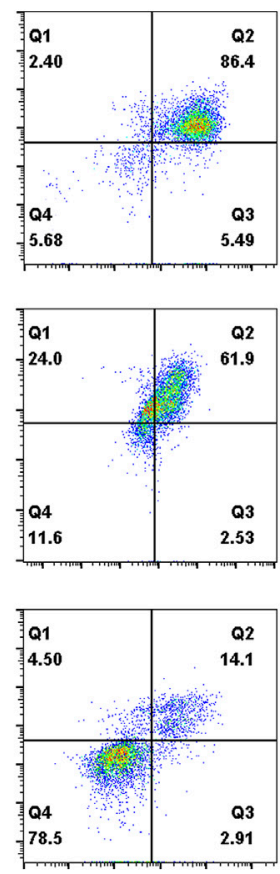

\section{Annexin V}

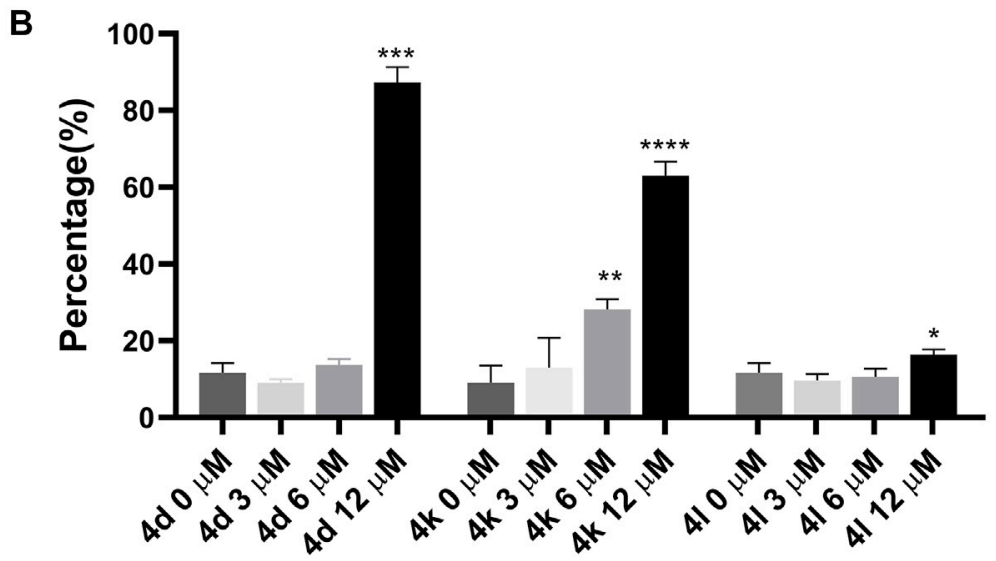

FIGURE 4 | Compound 4d, 4k, and $4 \mathrm{l}$ induced apoptosis of HeLa cells. (A) HeLa cells were exposed to compound $4 \mathrm{n}$ for $72 \mathrm{~h}$. (B) Flow cytometry analysis data from three independent experiments were summarized and shown. $0 \mu \mathrm{M}$, negative control. ${ }^{*} p$ value $<0.05,{ }^{\star \star} p$-value $<0.01,{ }^{\star \star \star *} p$-value $<0.001$ and ${ }^{\star \star \star \star *} p$-value $<0.0001$ ( $t$-test).

\section{RESULTS AND DISCUSSION}

\section{Inhibition of HeLa Cells by}

\section{Erlotinib-1,2,3-Triazole Derivatives}

As demonstrated in Table 1, antitumor activity showed that six compounds exhibited higher antitumor activity than erlotinib, such as $\mathbf{4 d}\left(\mathrm{IC}_{50}=7.02 \mu \mathrm{M}\right), \mathbf{4 i}\left(\mathrm{IC}_{50}=4.36 \mu \mathrm{M}\right), \mathbf{4 k}$ $\left(\mathrm{IC}_{50}=4.16 \mu \mathrm{M}\right), 4 \mathrm{l}\left(\mathrm{IC}_{50}=4.51 \mu \mathrm{M}\right), 4 \mathrm{~m}\left(\mathrm{IC}_{50}=3.79 \mu \mathrm{M}\right)$, and $4 \mathrm{n}\left(\mathrm{IC}_{50}=8.21 \mu \mathrm{M}\right)$, indicating that the introduction of triazole enhanced the antitumor activity of HeLa.

\section{Cell Apoptosis Assay}

To clarify whether the antiproliferative efficacy of the new compounds was associated with apoptosis, HeLa cells were treated with compounds $4 \mathrm{~d}, 4 \mathrm{k}$, and $4 \mathrm{l}(3,6$, and $12 \mu \mathrm{M})$ for $72 \mathrm{~h}$, respectively, and then detected by flow cytometry. As shown in Figure 4, high concentration $(12 \mu \mathrm{M})$ of $4 \mathrm{~d}$ and $4 \mathrm{l}$ induced significant cell apoptosis in HeLa cells with percentages of $87.28 \%$ and $16.36 \%$, respectively, and 6 and $12 \mu \mathrm{M}$ of $4 \mathrm{~d}$ induced significant cell apoptosis in HeLa cells with percentages of $28.21 \%$ and $62.96 \%$, respectively. 


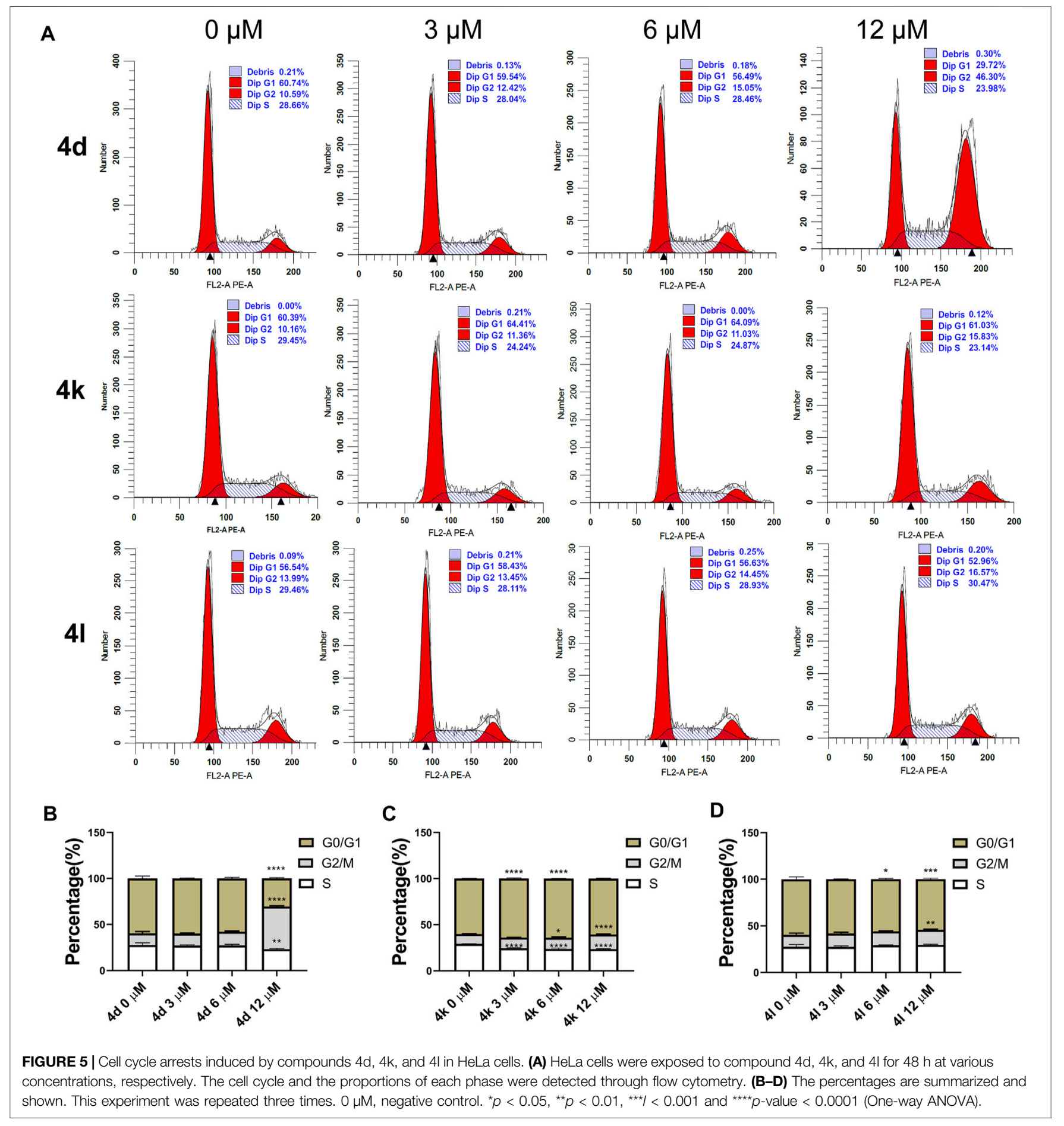

Therefore, $4 \mathrm{~d}$ and $4 \mathrm{k}$ showed more robust efficacy in inducing HeLa cell apoptosis than 41 .

\section{Cell Cycle Assay}

To investigate the effects of compounds $4 \mathrm{~d}, 4 \mathrm{k}$, and $4 \mathrm{l}$ on various phases of cell cycle, HeLa cells were treated with various concentrations of compounds $4 \mathrm{~d}, 4 \mathrm{k}$, and $4 \mathrm{l}$ for $48 \mathrm{~h}$. As shown in Figure 5, the results of flow cytometry indicated that $4 \mathrm{~d}$ and $4 \mathrm{~L}$ induced higher percentages of HeLa cells in $\mathrm{G} 2 / \mathrm{M}$ phrases at the concentration of $12 \mu \mathrm{M}$. However, $3 \mu \mathrm{M}$ of compound $4 \mathrm{k}$ arrested HeLa cells at G0/G1 phrases, $12 \mu \mathrm{M}$ of compounds $4 \mathrm{k}$ arrested HeLa cells at G2/M phrases, but $6 \mu \mathrm{M}$ of compounds $4 \mathrm{k}$ arrested HeLa cells at both G0/G1 and $\mathrm{G} 2 / \mathrm{M}$. The results confirmed that compounds $4 \mathrm{~d}, 4 \mathrm{k}$, and $4 \mathrm{l}$ 

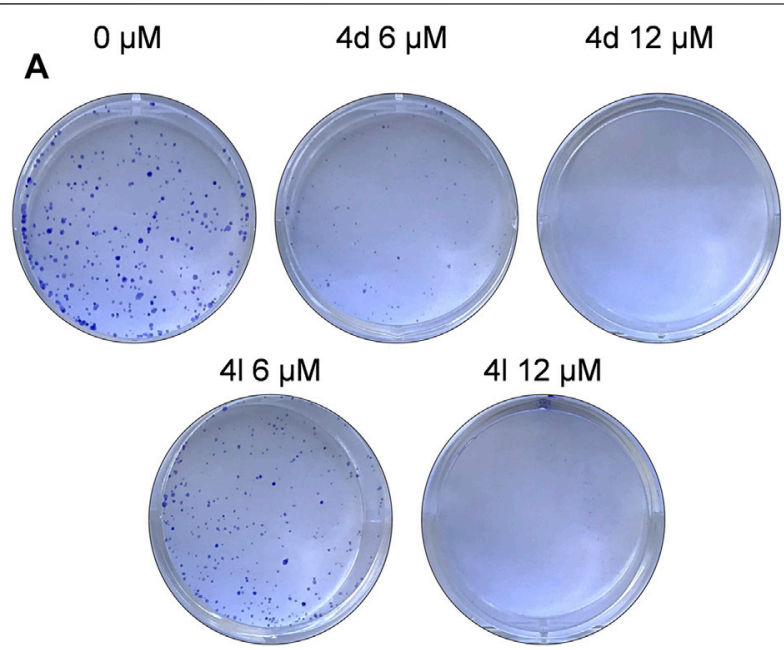

$4 \mathrm{l} 12 \mu \mathrm{M}$

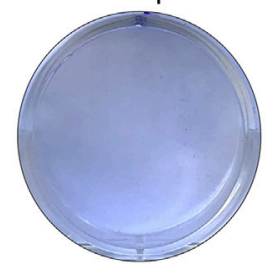

FIGURE 6 | Compounds 4d and 4 inhibited cell survival in the colony formation assay. (A) Colony formation assay results. Images represents wells of HeLa cells exposed to each treatment. (B) Quantitative analysis of colony formation assay. The experiments were preformed three times. ${ }^{*} p>0.05,{ }^{* *} p>0.01,{ }^{\star \star *} p>0.001(t$-test).

TABLE 2 | EGFR inhibitory activities of the derivatives.

\begin{tabular}{lcccccc} 
Compd no & $\mathbf{N}$ & $\mathbf{R}^{\mathbf{1}}$ & $\boldsymbol{R}^{\mathbf{2}}$ & $\mathbf{R}^{\mathbf{3}}$ & $\mathbf{R}^{\mathbf{4}}$ & $\begin{array}{c}\mathbf{I C}_{\mathbf{5 0}}(\boldsymbol{\mu M}) \\
\text { EGFR }\end{array}$ \\
\hline 4d & 1 & $\mathrm{H}$ & $\mathrm{Br}$ & $\mathrm{H}$ & $\mathrm{Br}$ & 13.01 \\
$4 \mathrm{k}$ & 0 & $\mathrm{OCH}_{3}$ & $\mathrm{H}$ & $\mathrm{H}$ & $\mathrm{H}$ & 49.39 \\
4 I & 0 & $\mathrm{H}$ & $\mathrm{H}$ & $\mathrm{CH}_{3}$ & $\mathrm{H}$ & 1.76 \\
Erlotinib & - & - & - & - & - & 0.0048
\end{tabular}

Kinase inhibitory activities of the compounds were evaluated using the enzyme-linked immunosorbent assay (ELISA).

can inhibit the proliferation of HeLa cells through cell cycle arrests.

\section{Colony Formation Assay}

To further evaluate the antiproliferation activities of these new compounds against HeLa cells, colony formation assay was performed. As the results demonstrated in Figure 6, compounds $4 \mathrm{~d}$ and $4 \mathrm{l}$ entirely inhibited the cell colony formation at the concentration of $12 \mu \mathrm{M}$, but compound $4 \mathrm{~d}$ can decrease the number of colonies at the concentration of $6 \mu \mathrm{M}$ as well, suggesting that these compounds impeded the survival and proliferation of HeLa cells.

\section{EGFR Inhibition Study}

To clarify whether the antiproliferative efficacy of the new compounds was associated with EGFR inhibitory activities, compound $4 \mathrm{~d}, 4 \mathrm{k}$, and $4 \mathrm{l}$ were assayed for their activities to inhibit EGFR tyrosine phosphorylation in vitro using ELISA. Erlotinib served as a positive control. The results were shown as $\mathrm{IC}_{50}$ values in Table 2. Under these conditions, the $\mathrm{IC}_{50}$ of erlotinib was $4.8 \mathrm{nM}$, which was similar to previously reported values (Moyer et al., 1997; Akita and Sliwkowski 2003) $\left(\mathrm{IC}_{50}=2 \mathrm{nM}\right)$. As illustrated in Table 2, compounds $4 \mathrm{~d}$ and $4 \mathrm{l}$ showed more ability to inhibit EGFR tyrosine phosphorylation with the $\mathrm{IC}_{50}$ values of 13.01 and $1.76 \mu \mathrm{M}$.

\section{CONCLUSION}

In summary, a series of erlotinib derivatives containing 1,2,3triazole rings were prepared and evaluated for the antiproliferative activities against HeLa cells. Some of the compounds exhibited better antiproliferation activities than the parent erlotinib. Besides, $4 \mathbf{d}\left(\mathrm{IC}_{50}=7.02 \mu \mathrm{M}\right)$, $4 \mathbf{k}\left(\mathrm{IC}_{50}\right.$ $=4.16 \mu \mathrm{M})$, and $4 \mathrm{l}\left(\mathrm{IC}_{50}=4.51 \mu \mathrm{M}\right)$ were demonstrated to induce apoptosis and cell cycle arrests in HeLa cells. In addition, $4 \mathrm{~d}$ and $4 \mathrm{l}$ proved to impeded the survival and proliferation of HeLa cells by colony formation assay and showed considerable EGFR inhibitory activity. Therefore, these erlotinib-1,2,3-triazole compounds with potent anticancer activities may serve as novel antitumor agents against cervical cancer, and additional mechanisms merit further investigation.

\section{EXPERIMENTAL PROTOCOLS}

\section{Materials and Chemistry}

Erlotinib-1,2,3-triazole derivatives were in-house synthesized. All compounds were purchased from Aladdin's reagent (China). All reagents and solvents obtained from commercially available source were used without further treatment. ${ }^{1} \mathrm{H}$ NMR and ${ }^{13} \mathrm{C}$ NMR spectra were acquired in DMSO- $\mathrm{d}_{6}$ solution with a Bruker 600 spectrometer. Chemical shifts (d) were given in parts per million with tetramethylsilane as internal reference, and coupling constants were expressed in Hertz. HR MS measurements were carried out using a Bruker MicrOTOF-Q II mass spectrometer. HeLa cell line, Dulbecco's modified Eagle's medium (DMEM) medium, and fetal bovine serum were purchased from ATCC (Virginia, United States). 


\section{General Procedure for the Synthesis of Analogues 4a-4n \\ General Procedure for Preparation of Compound 2}

Compound 1 (30g, $0.1 \mathrm{~mol}$ ) was added to a solution of dimethylformamide (DMF) $(5 \mathrm{~g})$ and thionylchloride $(400 \mathrm{ml})$ at room temperature; then, the suspension was raised to $80^{\circ} \mathrm{C}$ and stirred for $3 \mathrm{~h}$ under nitrogen. After that, the mixture was cooled to $0^{\circ} \mathrm{C}-10^{\circ} \mathrm{C}$, adjusted to $\mathrm{pH} 7-9$ with aqueous $\mathrm{NaOH}$ and extracted with dichloromethane $(200 \mathrm{ml})$. The organic was washed with aqueous $\mathrm{NaCl}$ and evaporated to yield compound 2 as a $\tan$ solid.

\section{General Procedure for Preparation of Erlotinib (Compound 3)}

3-Aminophenylacetylene $(1.2 \mathrm{~g}, 0.01 \mathrm{~mol})$ was added to a suspension of compound $2(3 \mathrm{~g}, 0.01 \mathrm{~mol})$ and isopropanol alcohol $(50 \mathrm{ml})$; then, the mixture was stirred at $85^{\circ} \mathrm{C}$ for $6 \mathrm{~h}$ under nitrogen. Solid gradually separated, and the reaction was monitored with thin-layer chromatography (TLC). After the completion of the reaction, the reaction mixture was transferred to ice water and stirred for half an hour. The solid was collected by filtration and was washed twice with isopropanol ( $30 \mathrm{ml}$ ) to give $2.1 \mathrm{~g}$ of erlotinib. ${ }^{1} \mathrm{H}$ NMR $\left(600 \mathrm{MHz}\right.$, DMSO- $\left.\mathrm{d}_{6}\right)$ : $\delta 9.48(\mathrm{~s}, 1 \mathrm{H}), 8.51(\mathrm{~s}, 1 \mathrm{H}), 8.00(\mathrm{~s}, 1 \mathrm{H}), 7.91(\mathrm{~d}, \mathrm{~J}=9.5 \mathrm{~Hz}, 1 \mathrm{H})$, $7.87(\mathrm{~s}, 1 \mathrm{H}), 7.41(\mathrm{t}, \mathrm{J}=7.9 \mathrm{~Hz}, 1 \mathrm{H}), 7.27-7.17(\mathrm{~m}, 2 \mathrm{H}), 4.30(\mathrm{~d}, \mathrm{~J}$ $=15.1 \mathrm{~Hz}, 4 \mathrm{H}), 4.21(\mathrm{~s}, 1 \mathrm{H}), 3.78(\mathrm{~d}, \mathrm{~J}=31.1 \mathrm{~Hz}, 4 \mathrm{H}), 3.38(\mathrm{~s}, 3 \mathrm{H})$, $3.36(\mathrm{~s}, 3 \mathrm{H}) ;{ }^{13} \mathrm{C}$ NMR $\left(150 \mathrm{~Hz}\right.$, DMSO-d $\left.\mathrm{d}_{6}\right): 156.59,154.15,153.27$, $148.61,147.49,140.28,129.37,126.81,125.21,123.02,122.21$, $109.39,108.69,103.65,83.97,81.03,70.59,70.52,68.85,68.52$, 58.87, 58.82; HRMS (ESI) m/z: calcd for $\mathrm{C}_{22} \mathrm{H}_{23} \mathrm{O}_{4} \mathrm{~N}_{3} \mathrm{Na}$ [M $+\mathrm{Na}]^{+} 416.1581$, found 416.1585 .

\section{General Procedure for Preparation of Compounds 4a-4n}

Erlotinib (1.0 mmol) and aryl-azido $(1.2 \mathrm{mmol})$ were added to a mixed solvent (water:tert-butanol $=2: 1,30 \mathrm{ml})$. Cuprous iodide $(0.1 \mathrm{mmol}$ ) was added to the mixture, and the reaction was stirred at $80^{\circ} \mathrm{C}$. After completion of the reaction (monitored by TLC), the mixture was extracted with dichloromethane $(20 \mathrm{ml} \times 3)$.The combined organic phase was washed successively with water and brine, then dried with anhydrous sodium sulfate and desolventized. The residue was purified by column chromatography $\left(\mathrm{CH}_{2} \mathrm{Cl}_{2} / \mathrm{MeOH}=30: 1\right)$ to obtain the desired compound $\mathbf{4}$ as a crystalline powder.

[3-(1-Benzyl-1H-[1,2,3]triazol-4-yl)-phenyl]-[6,7-bis-(2-methoxyethoxy)-quinazolin-4-yl]-amine (4a). m.p.89-92 ${ }^{\circ} \mathrm{C} ;{ }^{1} \mathrm{H} \quad \mathrm{NMR}$ $\left(600 \mathrm{MHz}, \mathrm{DMSO}-\mathrm{d}_{6}\right): \delta 9.56(\mathrm{~s}, 1 \mathrm{H}), 8.67(\mathrm{~s}, 1 \mathrm{H}), 8.49(\mathrm{~s}, 1 \mathrm{H})$, $8.27(\mathrm{~s}, 1 \mathrm{H}), 7.95-7.86(\mathrm{~m}, 2 \mathrm{H}), 7.56(\mathrm{~d}, \mathrm{~J}=7.7 \mathrm{~Hz}, 1 \mathrm{H}), 7.51-7.28$ (m, 6H), $7.24(\mathrm{~s}, 1 \mathrm{H}), 5.67(\mathrm{~s}, 2 \mathrm{H}), 4.31(\mathrm{~d}, J=21.7 \mathrm{~Hz}, 4 \mathrm{H}), 3.78$ $(\mathrm{d}, J=32.4 \mathrm{~Hz}, 4 \mathrm{H}), 3.39$ (s, $3 \mathrm{H}), 3.36(\mathrm{~s}, 3 \mathrm{H}) .{ }^{13} \mathrm{C}$ NMR $(150 \mathrm{~Hz}$, DMSO-d d $_{6}$ ): 156.83, 154.06, 153.40, 148.56, 147.44, 147.12, 140.52, $136.50,131.39,129.48,129.30,128.66,128.42,122.28,122.12$, $120.79,119.23,109.43,108.68,103.69,70.60,70.54,68.83,68.51$, 58.88, 58.82, 53.53; HR MS (ESI) m/z: calcd for $\mathrm{C}_{29} \mathrm{H}_{30} \mathrm{O}_{4} \mathrm{~N}_{6} \mathrm{Na}$ $[\mathrm{M}+\mathrm{Na}]^{+} 549.2221$, found 549.2231 .

[6,7-Bis-(2-methoxy-ethoxy)-quinazolin-4-yl] -\{3-[1-(2-iodobenzyl)-1H-[1,2,3]triazol-4-yl]-phenyl\}-amine (4b). m.p.93-
$96{ }^{\circ} \mathrm{C} ;{ }^{1} \mathrm{H}$ NMR (600 MHz, DMSO-d $\left.{ }_{6}\right): \delta 9.63(\mathrm{~s}, 1 \mathrm{H}), 8.64(\mathrm{~s}$, $1 \mathrm{H}), 8.54(\mathrm{~s}, 1 \mathrm{H}), 8.32(\mathrm{~s}, 1 \mathrm{H}), 8.06-7.90(\mathrm{~m}, 3 \mathrm{H}), 7.63(\mathrm{~d}$, $J=7.7 \mathrm{~Hz}, 1 \mathrm{H}), 7.50(\mathrm{dd}, J=16.4,8.0 \mathrm{~Hz}, 2 \mathrm{H}), 7.28(\mathrm{~s}, 1 \mathrm{H}), 7.20$ (dd, $J=11.8,7.6 \mathrm{~Hz}, 2 \mathrm{H}), 5.75(\mathrm{~s}, 2 \mathrm{H}), 4.35(\mathrm{~d}, J=20.8 \mathrm{~Hz}, 4 \mathrm{H})$, $3.83(\mathrm{~d}, J=31.5 \mathrm{~Hz}, 4 \mathrm{H}), 3.43(\mathrm{~s}, 3 \mathrm{H}), 3.41(\mathrm{~s}, 3 \mathrm{H}) .{ }^{13} \mathrm{C} \mathrm{NMR}$ $\left(150 \mathrm{~Hz}, \mathrm{DMSO}-\mathrm{d}_{6}\right): 156.86,154.09,153.34,148.57,147.30$, $146.93,140.50,140.00,138.36,131.32,130.80,130.17,129.49$, $129.38,122.52,122.38,120.88,119.30,109.42,108.58,103.72$, 99.70, 70.59, 70.54, 68.84, 68.52, 58.88, 58.83, 58.03; HR MS (ESI) $\mathrm{m} / \mathrm{z}$ : calcd for $\mathrm{C}_{29} \mathrm{H}_{29} \mathrm{O}_{4} \mathrm{~N}_{6} \mathrm{INa}[\mathrm{M}+\mathrm{Na}]^{+}$675.1187, found 675.1196 .

[6,7-Bis-(2-methoxy-ethoxy)-quinazolin-4-yl]-\{3-[1-(2bromo-benzyl)-1H-[1,2,3] triazol-4-yl]-phenyl $\}$-amine (4c). m.p. $94-97^{\circ} \mathrm{C} ;{ }^{1} \mathrm{H}$ NMR $\left(600 \mathrm{MHz}, \mathrm{DMSO}-\mathrm{d}_{6}\right): \delta 9.60(\mathrm{~s}, 1 \mathrm{H}), 8.63$ $(\mathrm{s}, 1 \mathrm{H}), 8.50(\mathrm{~s}, 1 \mathrm{H}), 8.27(\mathrm{~s}, 1 \mathrm{H}), 7.98-7.84(\mathrm{~m}, 2 \mathrm{H}), 7.72(\mathrm{~d}$, $J=7.9 \mathrm{~Hz}, 1 \mathrm{H}), 7.58(\mathrm{~d}, J=7.7 \mathrm{~Hz}, 1 \mathrm{H}), 7.46(\mathrm{dt}, J=11.5,7.7 \mathrm{~Hz}$, $2 \mathrm{H}), 7.34(\mathrm{t}, \mathrm{J}=8.3 \mathrm{~Hz}, 1 \mathrm{H}), 7.29-7.16(\mathrm{~m}, 2 \mathrm{H}), 5.76(\mathrm{~s}, 2 \mathrm{H}), 4.31$ $(\mathrm{d}, J=20.5 \mathrm{~Hz}, 4 \mathrm{H}), 3.78(\mathrm{~d}, J=31.6 \mathrm{~Hz}, 4 \mathrm{H}), 3.38(\mathrm{~s}, 3 \mathrm{H}), 3.36$ (s, 3H). ${ }^{13} \mathrm{C}$ NMR $(150 \mathrm{~Hz}$, DMSO-d 6 ): 156.88, 154.10, 153.31, $148.58,147.22,146.92,140.47,135.28,133.42,131.32,131.00$, $129.94,129.50,128.83,123.37,122.53,122.41,120.91,119.33$, $109.41,108.53,103.72,87.36,70.60,70.53,68.84,68.52,58.88$, 58.83, 53.63; HR MS (ESI) m/z: calcd for $\mathrm{C}_{29} \mathrm{H}_{29} \mathrm{O}_{4} \mathrm{~N}_{6} \mathrm{BrNa}[\mathrm{M}+$ $\mathrm{Na}]^{+}$627.1331, found 627.1336.

[6,7-Bis-(2-methoxy-ethoxy)-quinazolin-4-yl]-\{3-[1-(3,5dibromo-benzyl)-1H-[1,2,3]triazol-4-yl]-phenyl $\}$-amine (4d). m.p.102-105 ${ }^{\circ}$; ${ }^{1} \mathrm{H}$ NMR $\left(600 \mathrm{MHz}, \mathrm{DMSO}-\mathrm{d}_{6}\right): \delta 9.58$ (s, $1 \mathrm{H}$ ), $8.72(\mathrm{~s}, 1 \mathrm{H}), 8.49(\mathrm{~s}, 1 \mathrm{H}), 8.28(\mathrm{~s}, 1 \mathrm{H}), 7.99-7.89(\mathrm{~m}, 2 \mathrm{H}), 7.86(\mathrm{~s}$, $1 \mathrm{H}), 7.64(\mathrm{~s}, 2 \mathrm{H}), 7.57(\mathrm{~d}, J=7.6 \mathrm{~Hz}, 1 \mathrm{H}), 7.47(\mathrm{t}, J=7.9 \mathrm{~Hz}, 1 \mathrm{H})$, $7.24(\mathrm{~s}, 1 \mathrm{H}), 5.70(\mathrm{~s}, 2 \mathrm{H}), 4.35-4.26(\mathrm{~m}, 4 \mathrm{H}), 3.83-3.73(\mathrm{~m}, 4 \mathrm{H})$, $3.39(\mathrm{~s}, 3 \mathrm{H}), 3.36(\mathrm{~s}, 3 \mathrm{H}) ;{ }^{13} \mathrm{C}$ NMR $(150 \mathrm{~Hz}$, DMSO-d 6 ): 156.84, $154.06,153.39,148.56,147.45,147.22,140.83,140.56,133.73$, $131.21,130.67,129.51,123.23,122.41,120.83,119.30,109.44$, 108.68, 103.71, 70.61, 70.54, 68.84, 68.51, 58.88, 58.82, 52.01; HR MS(ESI)m/z: calcd for $\mathrm{C}_{29} \mathrm{H}_{29} \mathrm{O}_{4} \mathrm{~N}_{6} \mathrm{Br}_{2} \mathrm{Na}[\mathrm{M}+\mathrm{Na}]^{+} 683.0612$, found 683.0624 .

[6,7-Bis-(2-methoxy-ethoxy)-quinazolin-4-yl]-\{3-[1-(3-methoxyphenyl)-1H-[1,2,3]triazol-4-yl]-phenyl\}-amine (4e). m.p.85$88^{\circ} \mathrm{C} ;{ }^{1} \mathrm{H}$ NMR $\left(600 \mathrm{MHz}\right.$, DMSO-d $\left.\mathrm{d}_{6}\right): \delta 9.61(\mathrm{~s}, 1 \mathrm{H}), 8.66$ $(\mathrm{s}, 1 \mathrm{H}), 8.27(\mathrm{~s}, 1 \mathrm{H}), 8.01(\mathrm{~s}, 1 \mathrm{H}), 7.91(\mathrm{~d}, J=7.9 \mathrm{~Hz}, 1 \mathrm{H})$, $7.57(\mathrm{~d}, J=7.6 \mathrm{~Hz}, 1 \mathrm{H}), 7.46(\mathrm{t}, J=7.9 \mathrm{~Hz}, 1 \mathrm{H}), 7.32(\mathrm{t}, J=7.9 \mathrm{~Hz}$, $2 \mathrm{H}), 6.97(\mathrm{~s}, 1 \mathrm{H}), 6.93(\mathrm{~d}, J=7.9 \mathrm{~Hz}, 2 \mathrm{H}), 5.63(\mathrm{~s}, 2 \mathrm{H}), 4.32$ $(\mathrm{d}, J=9.1 \mathrm{~Hz}, 4 \mathrm{H}), 3.80(\mathrm{~d}, J=9.0 \mathrm{~Hz}, 4 \mathrm{H}), 3.76(\mathrm{~s}, 3 \mathrm{H}), 3.39$ $(\mathrm{s}, 3 \mathrm{H}), 3.37(\mathrm{~s}, 3 \mathrm{H}) .{ }^{13} \mathrm{C}$ NMR $\left(150 \mathrm{~Hz}\right.$, DMSO-d $\left.\mathrm{d}_{6}\right): 159.96$, $156.75,154.04,148.63,147.09,140.46,137.91,131.41,130.47$, $129.50,122.35,122.13,120.87,120.51,119.31,114.27,113.98$, $108.94,103.82,87.75,70.60,70.54,68.85,68.54,58.88,58.83$, 55.61, 53.46, 22.56; HR MS (ESI) $\mathrm{m} / \mathrm{z}$ : calcd for $\mathrm{C}_{30} \mathrm{H}_{33} \mathrm{O}_{5} \mathrm{~N}_{6}$ $[\mathrm{M}+\mathrm{H}]^{+}$557.2512, found 557.2508.

[6,7-Bis-(2-methoxy-ethoxy)-quinazolin-4-yl]-\{3-[1-(2-fluorophenyl)-1H-[1,2,3]triazol-4-yl]-phenyl\}-amine (4f). m.p.83$86^{\circ} \mathrm{C} ;{ }^{1} \mathrm{H}$ NMR $\left(600 \mathrm{MHz}\right.$, DMSO-d $\left.{ }_{6}\right): \delta 9.62(\mathrm{~s}, 1 \mathrm{H}), 9.11$ (s, $1 \mathrm{H}), 8.51(\mathrm{~s}, 1 \mathrm{H}), 8.39(\mathrm{~s}, 1 \mathrm{H}), 8.04-7.86(\mathrm{~m}, 3 \mathrm{H}), 7.73-7.59(\mathrm{~m}$, $3 \mathrm{H}), 7.56-7.46(\mathrm{~m}, 2 \mathrm{H}), 7.25(\mathrm{~s}, 1 \mathrm{H}), 4.37-4.28(\mathrm{~m}, 4 \mathrm{H})$, $3.83-3.74(\mathrm{~m}, 4 \mathrm{H}), 3.39(\mathrm{~s}, 3 \mathrm{H}), 3.37(\mathrm{~s}, 3 \mathrm{H}) .{ }^{13} \mathrm{C}$ NMR $(150 \mathrm{~Hz}$, DMSO- $\left.\mathrm{d}_{6}\right): 156.85,155.22,154.08,153.41,148.57,147.40,140.64$, $131.88,130.76,129.61,126.56,126.08,123.40,122.74,121.08$, 
$119.48,117.75,117.62,109.46,108.69,103.71,70.61,70.54,68.85$, 68.51, 58.88, 58.82; HR MS (ESI) m/z: calcd for $\mathrm{C}_{28} \mathrm{H}_{27} \mathrm{O}_{4} \mathrm{~N}_{6} \mathrm{FNa}$ $[\mathrm{M}+\mathrm{Na}]^{+}$553.1970, found 553.1979.

[6,7-Bis-(2-methoxy-ethoxy)-quinazolin-4-yl]-\{3-[1-(4-fluorophenyl)-1H-[1,2,3]triazol-4-yl]-phenyl -amine (4g). m.p.88-91 ${ }^{\circ} \mathrm{C}$; ${ }^{1} \mathrm{H}$ NMR $\left(600 \mathrm{MHz}, \mathrm{DMSO}-\mathrm{d}_{6}\right): \delta 9.73(\mathrm{~s}, 1 \mathrm{H}), 9.32(\mathrm{~s}, 1 \mathrm{H}), 8.57$ $(\mathrm{s}, 1 \mathrm{H}), 8.38(\mathrm{~s}, 1 \mathrm{H}), 8.14-7.86(\mathrm{~m}, 4 \mathrm{H}), 7.67(\mathrm{~d}, J=7.6 \mathrm{~Hz}, 1 \mathrm{H})$, $7.52(\mathrm{dt}, J=12.5,8.3 \mathrm{~Hz}, 3 \mathrm{H}), 7.26(\mathrm{~s}, 1 \mathrm{H}), 4.41-4.25(\mathrm{~m}, 4 \mathrm{H})$, 3.85 - 3.72 (m, 4H), 3.39 (s, 3H), 3.37 (s, 3H); ${ }^{13} \mathrm{C} \mathrm{NMR}(150 \mathrm{~Hz}$, DMSO-d $)_{6}$ : 162.98, 161.35, 156.98, 156.96, 154.21, 153.11, 148.67, $147.80,140.47,133.71,130.95,129.63,122.88,122.82,120.45$, $119.61,117.36,117.20,108.32,103.79,70.59,70.53,68.87$, 68.57, 58.89, 58.83; HR MS (ESI) m/z: calcd for $\mathrm{C}_{28} \mathrm{H}_{27} \mathrm{O}_{4} \mathrm{~N}_{6} \mathrm{FNa}[\mathrm{M}+\mathrm{Na}]^{+}$553.1970, found 553.1979.

[6,7-Bis-(2-methoxy-ethoxy)-quinazolin-4-yl]-\{3-[1-(2-chlorophenyl)-1H-[1,2,3]triazol-4-yl]-phenyl $\}$-amine (4h). m.p.131$134^{\circ} \mathrm{C} ;{ }^{1} \mathrm{H}$ NMR $\left(600 \mathrm{MHz}, \mathrm{DMSO}-\mathrm{d}_{6}\right): \delta 9.62(\mathrm{~s}, 1 \mathrm{H}), 9.08(\mathrm{~s}$, $1 \mathrm{H}), 8.51(\mathrm{~s}, 1 \mathrm{H}), 8.40(\mathrm{~s}, 1 \mathrm{H}), 7.94(\mathrm{~d}, J=10.6 \mathrm{~Hz}, 2 \mathrm{H}), 7.85-7.79$ $(\mathrm{m}, 2 \mathrm{H}), 7.70-7.61(\mathrm{~m}, 3 \mathrm{H}), 7.52(\mathrm{t}, J=7.9 \mathrm{~Hz}, 1 \mathrm{H}), 7.25(\mathrm{~s}, 1 \mathrm{H})$, 4.36 - 4.27 (m, 4H), $3.84-3.74(\mathrm{~m}, 4 \mathrm{H}), 3.39$ (s, 3H), $3.37(\mathrm{~s}, 3 \mathrm{H})$; ${ }^{13} \mathrm{C}$ NMR $\left(150 \mathrm{~Hz}, \mathrm{DMSO}-\mathrm{d}_{6}\right): 156.86,154.09,153.40,148.58$, $147.44,146.99,140.64,135.03,131.08,130.89,129.61,129.13$, $129.01,128.96,124.19,122.67,121.04,119.48,109.44,108.66$, 103.72, 70.61, 70.54, 68.85, 68.52, 58.88, 58.83; HR MS (ESI) $\mathrm{m} / \mathrm{z}$ : calcd for $\mathrm{C}_{28} \mathrm{H}_{27} \mathrm{O}_{4} \mathrm{~N}_{6} \mathrm{ClNa}[\mathrm{M}+\mathrm{Na}]^{+} 569.1675$, found 569.1678 .

[6,7-Bis-(2-methoxy-ethoxy)-quinazolin-4-yl]-\{3-[1-(2-bromophenyl)-1H-[1,2,3]triazol-4-yl]-phenyl -amine (4i). m.p.93-97 ${ }^{\circ} \mathrm{C}$; ${ }^{1} \mathrm{H}$ NMR $\left(600 \mathrm{MHz}, \mathrm{DMSO}-\mathrm{d}_{6}\right): \delta 9.63(\mathrm{~s}, 1 \mathrm{H}), 9.05(\mathrm{~s}, 1 \mathrm{H})$, $8.51(\mathrm{~s}, 1 \mathrm{H}), 8.40(\mathrm{~s}, 1 \mathrm{H}), 8.00-7.89(\mathrm{~m}, 3 \mathrm{H}), 7.77$ (dd, $J=7.8$, $1.5 \mathrm{~Hz}, 1 \mathrm{H}), 7.67(\mathrm{t}, J=7.7 \mathrm{~Hz}, 2 \mathrm{H}), 7.60(\mathrm{t}, J=8.6 \mathrm{~Hz}, 1 \mathrm{H}), 7.52(\mathrm{t}$, $J=7.9 \mathrm{~Hz}, 1 \mathrm{H}), 7.25(\mathrm{~s}, 1 \mathrm{H}), 4.35-4.27(\mathrm{~m}, 4 \mathrm{H}), 3.83-3.75(\mathrm{~m}$, $4 \mathrm{H}), 3.39$ (s, 3H), 3.37 (s, 3H); ${ }^{13} \mathrm{C}$ NMR (150Hz, DMSO-d 6 ): $156.87,154.10,153.39,148.58,147.40,146.92,140.63,136.72$, $134.14,132.58,130.94,129.61,129.49,129.24,124.20,122.64$, $121.02,119.47,109.44,108.64,103.72,100.00,70.61,70.54$, 68.85, 68.52, 58.88, 58.83; HR MS (ESI) m/z: calcd for $\mathrm{C}_{28} \mathrm{H}_{27} \mathrm{O}_{4} \mathrm{~N}_{6} \mathrm{BrNa}[\mathrm{M}+\mathrm{Na}]^{+}$613.1169, found 613.1180.

[6,7-Bis-(2-methoxy-ethoxy)-quinazolin-4-yl]-\{3-[1-(4-bromophenyl)-1H-[1,2,3]triazol-4-yl]-phenyl $\}$-amine (4j). m.p.105$108^{\circ} \mathrm{C} ;{ }^{1} \mathrm{H}$ NMR $\left(600 \mathrm{MHz}, \mathrm{DMSO}-\mathrm{d}_{6}\right): \delta 9.63(\mathrm{~s}, 1 \mathrm{H}), 9.37(\mathrm{~s}$, $1 \mathrm{H}), 8.51(\mathrm{~s}, 1 \mathrm{H}), 8.38(\mathrm{~s}, 1 \mathrm{H}), 7.96(\mathrm{dd}, \mathrm{J}=16.5,7.6 \mathrm{~Hz}, 4 \mathrm{H}), 7.86$ $(\mathrm{d}, J=8.8 \mathrm{~Hz}, 2 \mathrm{H}), 7.66(\mathrm{~d}, J=7.6 \mathrm{~Hz}, 1 \mathrm{H}), 7.53(\mathrm{t}, J=7.9 \mathrm{~Hz}, 1 \mathrm{H})$, $7.25(\mathrm{~s}, 1 \mathrm{H}), 4.32(\mathrm{~d}, J=24.8 \mathrm{~Hz}, 4 \mathrm{H}), 3.79(\mathrm{~d}, J=34.8 \mathrm{~Hz}, 4 \mathrm{H}), 3.39$ $(\mathrm{s}, 3 \mathrm{H}), 3.37(\mathrm{~s}, 3 \mathrm{H}) ;{ }^{13} \mathrm{C}$ NMR $\left(150 \mathrm{~Hz}, \mathrm{DMSO}-\mathrm{d}_{6}\right): 156.86,154.09$, $153.40,148.58,147.97,147.44,140.63,136.32,133.32,130.82$, $129.62,122.79,122.38,121.82,121.01,120.19,119.48,109.43$, $108.66,103.68,70.60,70.54,68.84,68.51,58.88,58.82$; HR $\mathrm{MS}(\mathrm{ESI}) \mathrm{m} / \mathrm{z}$ : calcd for $\mathrm{C}_{28} \mathrm{H}_{27} \mathrm{O}_{4} \mathrm{~N}_{6} \mathrm{BrNa}[\mathrm{M}+\mathrm{Na}]^{+}$613.1169, found 613.1177 .

[6,7-Bis-(2-methoxy-ethoxy)-quinazolin-4-yl]-\{3-[1-(2-methoxyphenyl)-1H-[1,2,3]triazol-4-yl]-phenyl -amine (4k). m.p.87$90^{\circ} \mathrm{C} ;{ }^{1} \mathrm{H}$ NMR $\left(600 \mathrm{MHz}, \mathrm{DMSO}_{-} \mathrm{d}_{6}\right): \delta 9.62(\mathrm{~s}, 1 \mathrm{H}), 8.94$ $(\mathrm{s}, 1 \mathrm{H}), 8.50(\mathrm{~s}, 1 \mathrm{H}), 8.36(\mathrm{~s}, 1 \mathrm{H}), 7.98-7.91(\mathrm{~m}, 2 \mathrm{H}), 7.69$ $(\mathrm{dd}, \mathrm{J}=21.0,7.7 \mathrm{~Hz}, 2 \mathrm{H}), 7.58(\mathrm{t}, J=7.9 \mathrm{~Hz}, 1 \mathrm{H}), 7.50$ (t, $J=7.9 \mathrm{~Hz}, 1 \mathrm{H}), 7.36(\mathrm{~d}, J=8.2 \mathrm{~Hz}, 1 \mathrm{H}), 7.25(\mathrm{~s}, 1 \mathrm{H}), 7.19$ (t, J = 7.6 Hz, 1H), $4.32(\mathrm{~d}, J=25.5 \mathrm{~Hz}, 4 \mathrm{H}), 3.90(\mathrm{~s}, 3 \mathrm{H}), 3.79$ $(\mathrm{d}, J=34.6 \mathrm{~Hz}, 4 \mathrm{H}), 3.39(\mathrm{~s}, 3 \mathrm{H}), 3.37(\mathrm{~s}, 3 \mathrm{H}) ;{ }^{13} \mathrm{C} \mathrm{NMR}(150 \mathrm{~Hz}$, DMSO-d $\left.{ }_{6}\right): 156.88,154.08,153.41,152.32,148.56,147.45,146.67$, $140.57,131.39,131.21,129.52,126.43,126.21,123.94,122.54$, $121.36,121.04,119.43,113.49,109.45,108.67,103.73,68.84$, 68.51, 58.88, 58.52, 56.65; HR MS (ESI) m/z: calcd for $\mathrm{C}_{29} \mathrm{H}_{30} \mathrm{O}_{5} \mathrm{~N}_{6} \mathrm{Na}[\mathrm{M}+\mathrm{Na}]^{+}$565.2170, found 565.2172.

[6,7-Bis-(2-methoxy-ethoxy)-quinazolin-4-yl]-[3-(1-p-tolyl$1 \mathrm{H}$-[1,2,3] triazol-4-yl)-phenyl]-amine (4l). m.p.95-98 ${ }^{\circ} \mathrm{C} ;{ }^{1} \mathrm{H}$ NMR $\left(600 \mathrm{MHz}, \mathrm{DMSO}_{6}\right.$ ): $\delta 9.63(\mathrm{~s}, 1 \mathrm{H}), 9.28(\mathrm{~s}, 1 \mathrm{H}), 8.51$ $(\mathrm{s}, 1 \mathrm{H}), 8.37(\mathrm{~s}, 1 \mathrm{H}), 7.95(\mathrm{~d}, J=9.9 \mathrm{~Hz}, 2 \mathrm{H}), 7.87(\mathrm{~d}, J=8.3 \mathrm{~Hz}$, $2 \mathrm{H}), 7.67(\mathrm{~d}, J=7.6 \mathrm{~Hz}, 1 \mathrm{H}), 7.52(\mathrm{t}, J=7.9 \mathrm{~Hz}, 1 \mathrm{H}), 7.45$ (d, $J=8.3 \mathrm{~Hz}, 2 \mathrm{H}), 7.25(\mathrm{~s}, 1 \mathrm{H}), 4.32(\mathrm{~d}, J=25.1 \mathrm{~Hz}, 4 \mathrm{H}), 3.79$ $(\mathrm{d}, J=35.1 \mathrm{~Hz}, 4 \mathrm{H}), 3.39(\mathrm{~s}, 3 \mathrm{H}), 3.37(\mathrm{~s}, 3 \mathrm{H}), 2.51(\mathrm{~s}, 3 \mathrm{H}) ;{ }^{13} \mathrm{C}$ NMR $\left(150 \mathrm{~Hz}\right.$, DMSO-d $\left.{ }_{6}\right): 156.88,154.09,153.40,148.58,147.70$, $147.40,140.59,138.83,134.89,131.06,130.75,129.57,122.69$, $121.02,120.36,120.02,119.46,109.43,108.64,103.69,70.60$, 70.54, 68.84, 68.52, 58.88, 58.82, 21.07; HR MS (ESI) m/z: calcd for $\mathrm{C}_{29} \mathrm{H}_{31} \mathrm{O}_{4} \mathrm{~N}_{6}[\mathrm{M}+\mathrm{H}]^{+}$527.2401, found 527.2410.

[6,7-Bis-(2-methoxy-ethoxy)-quinazolin-4-yl]-\{3-[1-(3-nitrophenyl)-1H-[1,2,3]triazol-4-yl]-phenyl $\}$-amine (4m). m.p.98$101^{\circ} \mathrm{C} ;{ }^{1} \mathrm{H}$ NMR $\left(600 \mathrm{MHz}, \mathrm{DMSO}-\mathrm{d}_{6}\right): \delta 9.64(\mathrm{~s}, 1 \mathrm{H}), 9.60(\mathrm{~s}$, $1 \mathrm{H}), 8.83(\mathrm{t}, J=2.1 \mathrm{~Hz}, 1 \mathrm{H}), 8.50(\mathrm{~d}, J=12.4 \mathrm{~Hz}, 2 \mathrm{H}), 8.41(\mathrm{~s}, 1 \mathrm{H})$, $8.37(\mathrm{~d}, J=7.5 \mathrm{~Hz}, 1 \mathrm{H}), 7.99-7.94(\mathrm{~m}, 3 \mathrm{H}), 7.69(\mathrm{~d}, J=7.8 \mathrm{~Hz}$, $1 \mathrm{H}), 7.55(\mathrm{t}, J=7.9 \mathrm{~Hz}, 1 \mathrm{H}), 7.25(\mathrm{~s}, 1 \mathrm{H}), 4.32(\mathrm{~d}, J=25.9 \mathrm{~Hz}, 4 \mathrm{H})$, $3.79(\mathrm{~d}, J=36.0 \mathrm{~Hz}, 4 \mathrm{H}), 3.39$ (s, $3 \mathrm{H}), 3.37$ (s, $3 \mathrm{H}) ;{ }^{13} \mathrm{C} \mathrm{NMR}$ $\left(150 \mathrm{~Hz}, \mathrm{DMSO}-\mathrm{d}_{6}\right): 156.86,154.09,153.40,149.06,148.59$, $147.45,140.67,137.70,132.09,130.64,129.68,126.40,123.61$, $122.92,121.03,120.61,119.55,115.08,109.43,108.66,103.67$, 70.61, 70.54, 68.84, 68.52, 58.88, 58.83; HR MS (ESI) m/z: calcd for $\mathrm{C}_{28} \mathrm{H}_{27} \mathrm{O}_{6} \mathrm{~N}_{7} \mathrm{Na}[\mathrm{M}+\mathrm{Na}]^{+} 580.1915$, found 580.1923 .

[6,7-Bis-(2-methoxy-ethoxy)-quinazolin-4-yl]-\{3-[1-(3-ethoxyphenyl)-1H-[1,2,3]triazol-4-yl]-phenyl $\}$-amine (4n). m.p.110$114^{\circ} \mathrm{C} ;{ }^{1} \mathrm{H}$ NMR $\left(600 \mathrm{MHz}, \mathrm{DMSO}-\mathrm{d}_{6}\right): \delta 9.63(\mathrm{~s}, 1 \mathrm{H}), 9.36$ (s, 1H), $8.51(\mathrm{~s}, 1 \mathrm{H}), 8.37(\mathrm{~s}, 1 \mathrm{H}), 7.95(\mathrm{~d}, J=10.1 \mathrm{~Hz}, 2 \mathrm{H})$, $7.67(\mathrm{~d}, J=7.7 \mathrm{~Hz}, 1 \mathrm{H}), 7.55(\mathrm{~d}, J=36.4 \mathrm{~Hz}, 4 \mathrm{H}), 7.25(\mathrm{~s}, 1 \mathrm{H}), 7.08$ $(\mathrm{d}, J=10.2 \mathrm{~Hz}, 1 \mathrm{H}), 4.32(\mathrm{~d}, J=24.9 \mathrm{~Hz}, 4 \mathrm{H}), 4.17(\mathrm{q}, J=7.0 \mathrm{~Hz}$, $2 \mathrm{H}), 3.79(\mathrm{~d}, J=35.2 \mathrm{~Hz}, 4 \mathrm{H}), 3.39(\mathrm{~s}, 3 \mathrm{H}), 3.37(\mathrm{~s}, 3 \mathrm{H}), 1.39(\mathrm{t}$, $J=7.0 \mathrm{~Hz}, 3 \mathrm{H}) ;{ }^{13} \mathrm{C}$ NMR $\left(150 \mathrm{~Hz}, \mathrm{DMSO}-\mathrm{d}_{6}\right): 159.98,156.87$, $154.08,153.42,148.57,147.84,147.49,140.61,138.13,131.37$, $130.97,129.59,122.77,121.01,120.19,119.48,115.27,112.27$, $109.46,108.69,106.46,103.68,70.61,70.54,68.84,68.51,64.12$, $58.88,58.82$, 15.02; HR MS (ESI) m/z: calcd for $\mathrm{C}_{30} \mathrm{H}_{32} \mathrm{O}_{5} \mathrm{~N}_{6} \mathrm{Na}$ $[\mathrm{M}+\mathrm{Na}]^{+}$579.2326, found 579.2332 .

\section{Cell Antiproliferative Activity Assay}

Cell antiproliferative activity was evaluated by the Cell Counting Kit-8 (CCK8, DOJINDO, Japan) assay. The cells were seeded at a density of 2,000 cells per well into 96 -well microplate in $100 \mu \mathrm{l}$ of growth medium. Cells were incubated at $37^{\circ} \mathrm{C}$ and $5 \% \mathrm{CO}_{2}$ overnight. The next day, $100 \mu \mathrm{l}$ per well of diluted inhibitor in growth medium was added with the final concentration from $0.1 \mathrm{nM}$ to $100 \mu \mathrm{M}$. The cells were treated with DMSO as control. A series of dilutions are made in $0.1 \%$ DMSO in assay medium so that the final concentration of DMSO is $0.1 \%$ in all of treatments. Cells were incubated at $37^{\circ} \mathrm{C}$ and $5 \% \mathrm{CO}_{2}$ for $48 \mathrm{~h}$. Then, $10 \mu \mathrm{l}$ of 
CCK8 was added to each well. The plates were incubated at $37^{\circ} \mathrm{C}$ for $2 \mathrm{~h}$; after that, the plates were recorded by measuring absorbance at $450 \mathrm{~nm}$ with the reference wavelength of $630 \mathrm{~nm}$ using an EnVision Multilabel Reader (PerkinElmer). The $\mathrm{IC}_{50}$ values were calculated using GraphPad Prism 6.0 software and determined by the concentration causing a halfmaximal percent activity. All assays were conducted with three parallel samples and three repetitions.

\section{Flow Cytometry Detection for Cell Apoptosis}

Cell-apoptosis analysis was carried out by flow cytometry using the Annexin V/PI apoptosis kit (Solarbio, China) according to the manufacturer's manual. Briefly, HeLa $\left(5 \times 10^{4} /\right.$ well $)$ cells were seeded in 12 -well plates for $24 \mathrm{~h}$ and then treated with $0.1 \%$ DMSO (as control) or various concentrations of compounds $4 \mathrm{~d}$, $4 \mathrm{k}$, and $4 \mathrm{l}$ for $72 \mathrm{~h}$, respectively. Cells were harvested, washed with PBS, and then incubated with $100 \mu \mathrm{l}$ of $1 \times$ Annexin V binding buffer containing $1 \mu \mathrm{l} \mathrm{FITC} \mathrm{Annexin} \mathrm{V} \mathrm{for} 10 \mathrm{~min}$ at RT in the dark. Cells were incubated for another $5 \mathrm{~min}$ at room temperature (RT) in the dark after $1 \mu \mathrm{l}$ PI was added. PBS $(200 \mu \mathrm{l})$ was added to each tube for flow cytometry analysis (BriCyte E6). The percentages of apoptotic cells were analyzed using FlowJo soft.

\section{Flow Cytometry Detection for Cell Cycle}

$\mathrm{HeLa}\left(5 \times 10^{4} /\right.$ well $)$ cells were seeded in 12 -well plates for $24 \mathrm{~h}$ and then treated with $0.1 \%$ DMSO (as control), compounds $4 \mathrm{~d}$, $4 \mathrm{k}$, and $4 \mathrm{l}$ of various concentrations for $48 \mathrm{~h}$, respectively. The treated cells were harvested, washed with PBS, and then stained using the cell-cycle staining kit [Multisciences (Lianke) Biotech] according to the manufacturer's manual. The distribution of cell-cycle phases with different DNA contents was determined by flow cytometry (BriCyte E6) and analyzed using ModFit LT software.

\section{Colony Formation Assay}

HeLa cells were seeded in six-well plates at the density of 500/ well for $24 \mathrm{~h}$, and then treated with $0.1 \%$ DMSO (as control), various concentrations of compounds $4 \mathrm{~d}, 4 \mathrm{k}$, and $4 \mathrm{l}$, respectively. The cells were incubated for 2 weeks in a $5 \%$ $\mathrm{CO}_{2}$ environment at $37^{\circ} \mathrm{C}$ for colony formation. The media was gently removed from each of the plates, and then each plate was washed with PBS twice. The colonies were fixed with $4 \%$ polyformaldehyde for $10 \mathrm{~min}$ and then wash the cells with $\mathrm{ddH}_{2} \mathrm{O}$ twice. Stain with $1 \mathrm{ml}$ Crystal Violet Staining Solution (Beyotime, China) for $10 \mathrm{~min}$. Wash excess crystal violet with $\mathrm{ddH}_{2} \mathrm{O}$ and allow dishes to dry. Take pictures of the plate and count the colonies.

\section{REFERENCES}

Akita, R. W., and Sliwkowski, M. X. (2003). Preclinical Studies with Erlotinib (Tarceva). Semin. Oncol. 30, 15-24. doi:10.1016/s00937754(03)70011-6

\section{EGFR Kinase Assay}

Kinase inhibitory activities of compounds were evaluated using the enzyme-linked immunosorbent assay (ELISA). The kinase enzyme of EGFR was purchased from Carna Bioscience (Kobe, Japan). A total of $10 \mathrm{ng} / \mathrm{ml}$ anti phosphotyrosine (PY713) antibody (abcam, Cambridge Science Park, United Kingdom) was precoated in 96well ELISA plates. Active kinases were incubated with indicated drugs in one $\mathrm{X}$ reaction buffer $(50 \mathrm{mmol} / \mathrm{L}$ HEPES $\mathrm{pH} 7.4$, $\left.20 \mathrm{mmol} / \mathrm{L} \quad \mathrm{MgCl}_{2}, \quad 0.1 \mathrm{mmol} / \mathrm{L} \quad \mathrm{MnCl}_{2}, \quad 1 \mathrm{mmol} / \mathrm{L} \quad \mathrm{DTT}\right)$ containing $20 \mu \mathrm{mol} / \mathrm{L}$ substrate (NH2-ETVYSEVRK-biotin) at $25^{\circ} \mathrm{C}$ for $1 \mathrm{~h}$. Then, a total of $3 \mu \mathrm{mol} / \mathrm{L}$ ATP was added, and the reaction was continued for $2 \mathrm{~h}$. The products of reaction were transferred into 96-well ELISA plates containing antibody and incubated at $25^{\circ} \mathrm{C}$ for $30 \mathrm{~min}$. After incubation, the wells were washed with $\mathrm{PBS}$ and then incubated with horseradish peroxidase (HRP)-conjugated streptavidin. The wells were visualized using $3,3^{\prime}, 5,5^{\prime}$-tetramethylbenzidine (TMB), and chromogenic reaction was ended with $2 \mathrm{~mol} / \mathrm{L} \mathrm{H}_{2} \mathrm{SO}_{4}$, the absorbance was read with a multimode plate reader (PerkinElmer, United States) at $450 \mathrm{~nm}$.

\section{DATA AVAILABILITY STATEMENT}

The original contributions presented in the study are included in the article/Supplementary Material. Further inquiries can be directed to the corresponding authors.

\section{AUTHOR CONTRIBUTIONS}

PD and GS carried out the experiments and wrote the manuscript with support from LM and JZ. MY devised the biological part of the study. LP designed the chemical experiments. LP, MY, and $\mathrm{KY}$ helped supervise the project and conceived the original idea.

\section{FUNDING}

This work was supported by the National Natural Science Foundation of China (No. 81972488), the Shenzhen Science and Technology Program (JCYJ20210324115209026), and the Scientific and Technological Project of Henan Province (No. 192102310142).

\section{SUPPLEMENTARY MATERIAL}

The Supplementary Material for this article can be found online at: https://www.frontiersin.org/articles/10.3389/fphar.2021.793905/ full\#supplementary-material

Bhatia, P., Sharma, V., Alam, O., Manaithiya, A., Alam, P., Kahksha, et al. (2020). Novel Quinazoline-Based EGFR Kinase Inhibitors: A Review Focussing on SAR and Molecular Docking Studies (2015-2019). Eur. J. Med. Chem. 204, 112640. doi:10.1016/j.ejmech.2020.112640

Bray, F., Ferlay, J., Soerjomataram, I., Siegel, R. L., Torre, L. A., and Jemal, A. (2018). Global Cancer Statistics 2018: GLOBOCAN Estimates of Incidence and 
Mortality Worldwide for 36 Cancers in 185 Countries. CA Cancer J. Clin. 68, 394-424. doi:10.3322/caac.21492

Chavan, P. V., Desai, U. V., Wadgaonkar, P. P., Tapase, S. R., Kodam, K. M., Choudhari, A., et al. (2019). Click Chemistry Based Multicomponent Approach in the Synthesis of Spirochromenocarbazole Tethered 1,2,3-triazoles as Potential Anticancer Agents. Bioorg. Chem. 85, 475-486. doi:10.1016/ j.bioorg.2019.01.070

Cohen, M. H., Williams, G. A., Sridhara, R., Chen, G., and Pazdur, R. (2003). FDA Drug Approval Summary: Gefitinib (ZD1839) (Iressa) Tablets. Oncologist 8, 303-306. doi:10.1634/theoncologist.8-4-303

Hill, E. K. (2020). Updates in Cervical Cancer Treatment. Clin. Obstet. Gynecol. 63 (1), 3-11. doi:10.1097/grf.0000000000000507

Hirsch, F. R., Scagliotti, G. V., Mulshine, J. L., Kwon, R., Curran, W. J., Wu, Y. L., et al. (2017). Lung Cancer: Current Therapies and New Targeted Treatments. Lancet 389, 299-311. doi:10.1016/s0140-6736(16)30958-8

Hong, V., Steinmetz, N. F., Manchester, M., and Finn, M. G. (2010). Labeling Live Cells by Copper-Catalyzed Alkyne-Aazide Click Chemistry. Bioconjug. Chem. 21, 1912-1916. doi:10.1021/bc100272z

Jänne, P. A., Yang, J. C.-H., Kim, D.-W., Planchard, D., Ohe, Y., Ramalingam, S. S., et al. (2015). AZD9291 in EGFR Inhibitor-Resistant Non-small-cell Lung Cancer. N. Engl. J. Med. 372, 1689-1699. doi:10.1056/NEJMoa1411817

Liontos, M., Kyriazoglou, A., Dimitriadis, I., Dimopoulos, M. A., and Bamias, A. (2019). Systemic Therapy in Cervical Cancer: 30 Years in Review. Crit. Rev. Oncol. Hematol. 137, 9-17. doi:10.1016/j.critrevonc.2019.02.009

Maddili, S. K., Katla, R., Kannekanti, V. K., Bejjanki, N. K., Tuniki, B., Zhou, C. H., et al. (2018). Molecular Interaction of Novel Benzothiazolyl Triazolium Analogues with Calf Thymus DNA and HSA-Their Biological Investigation as Potent Antimicrobial Agents. Eur. J. Med. Chem. 150, 228-247. doi:10.1016/ j.ejmech.2018.02.056

Mao, L., Sun, G., Zhao, J., Xu, G., Yuan, M., and Li, Y. M. (2020a). Design, Synthesis and Antitumor Activity of Icotinib Derivatives. Bioorg. Chem. 105, 104421. doi:10.1016/j.bioorg.2020.104421

Mao, L. F., Wang, Y. W., Zhao, J., Xu, G. Q., Yao, X. J., and Li, Y. M. (2020b). Discovery of Icotinib-1,2,3-Triazole Derivatives as Ido1 Inhibitors. Front. Pharmacol. 11, 579024. doi:10.3389/fphar.2020.579024

Mathew, M. P., Tan, E., Saeui, C. T., Bovonratwet, P., Liu, L., Bhattacharya, R., et al. (2015). Metabolic Glycoengineering Sensitizes Drug-Resistant Pancreatic Cancer Cells to Tyrosine Kinase Inhibitors Erlotinib and Gefitinib. Bioorg. Med. Chem. Lett. 25, 1223-1227. doi:10.1016/j.bmcl.2015.01.060

Moyer, J. D., Barbacci, E. G., Iwata, K. K., Arnold, L., Boman, B., Cunningham, A., et al. (1997). Induction of Apoptosis and Cell Cycle Arrest by CP-358,774, an Inhibitor of Epidermal Growth Factor Receptor Tyrosine Kinase. Cancer Res. $57,4838-4848$.

Qi, Z. Y., Hao, S. Y., Tian, H. Z., Bian, H. L., Hui, L., and Chen, S. W. (2020). Synthesis and Biological Evaluation of 1-(benzofuran-3-Yl)-4-(3,4,5Trimethoxyphenyl)-1h-1,2,3-Triazole Derivatives as Tubulin Polymerization Inhibitors. Bioorg. Chem. 94, 103392. doi:10.1016/j.bioorg.2019.103392

Qin, X., Li, Z., Yang, L., Liu, P., Hu, L., Zeng, C., et al. (2016). Discovery of New $[1,4]$ dioxino[2,3-F]quinazoline-Based Inhibitors of EGFR Including the
T790M/L858R Mutant. Bioorg. Med. Chem. 24, 2871-2881. doi:10.1016/ j.bmc.2016.01.003

Roskoski, R., Jr. (2014). The ErbB/HER Family of Protein-Tyrosine Kinases and Cancer. Pharmacol. Res. 79, 34-74. doi:10.1016/j.phrs.2013.11.002

Saeedi, M., Mohammadi-Khanaposhtani, M., Pourrabia, P., Razzaghi, N., Ghadimi, R., Imanparast, S., et al. (2019). Design and Synthesis of Novel Quinazolinone1,2,3-Triazole Hybrids as New Anti-diabetic Agents: In Vitro a-glucosidase Inhibition, Kinetic, and Docking Study. Bioorg. Chem. 83, 161-169. doi:10.1016/j.bioorg.2018.10.023

Safavi, M., Ashtari, A., Khalili, F., Mirfazli, S. S., Saeedi, M., Ardestani, S. K., et al. (2018). Novel Quinazolin-4(3h)-One Linked to 1,2,3-triazoles: Synthesis and Anticancer Activity. Chem. Biol. Drug Des. 92, 1373-1381. doi:10.1111/ cbdd. 13203

Schettino, C., Bareschino, M. A., Ricci, V., and Ciardiello, F. (2008). Erlotinib: an EGF Receptor Tyrosine Kinase Inhibitor in Non-small-cell Lung Cancer Treatment. Expert Rev. Respir. Med. 2, 167-178. doi:10.1586/17476348.2.2.167

Tan, C. S., Gilligan, D., and Pacey, S. (2015). Treatment Approaches for EGFRInhibitor-Resistant Patients with Non-small-cell Lung Cancer. Lancet OncolOncology 16, e447-e459. doi:10.1016/S1470-2045(15)00246-6

Thomopoulou, P., Sachs, J., Teusch, N., Mariappan, A., Gopalakrishnan, J., and Schmalz, H. G. (2015). New Colchicine-Derived Triazoles and Their Influence on Cytotoxicity and Microtubule Morphology. ACS Med. Chem. Lett. 7, 188-191. doi:10.1021/acsmedchemlett.5b00418

Yin, Y., Qiu, X. Y., Zhang, Y. H., and Zhang, B. (2019). A Rare Cutaneous Phototoxic Rash after Vandetanib Therapy in a Patient with Thyroid Cancer: A Case Report. Medicine (Baltimore) 98, e16392. doi:10.1097/ MD.0000000000016392

Zhang, H. Q., Gong, F. H., Ye, J. Q., Zhang, C., Yue, X. H., Li, C. G., et al. (2017). Design and Discovery of 4-Anilinoquinazoline-Urea Derivatives as Dual TK Inhibitors of EGFR and VEGFR-2. Eur. J. Med. Chem. 125, 245-254. doi:10.1016/j.ejmech.2016.09.039

Conflict of Interest: The authors declare that the research was conducted in the absence of any commercial or financial relationships that could be construed as a potential conflict of interest.

Publisher's Note: All claims expressed in this article are solely those of the authors and do not necessarily represent those of their affiliated organizations, or those of the publisher, the editors, and the reviewers. Any product that may be evaluated in this article, or claim that may be made by its manufacturer, is not guaranteed or endorsed by the publisher.

Copyright ( 2022 Deng, Sun, Zhao, Yao, Yuan, Peng and Mao. This is an openaccess article distributed under the terms of the Creative Commons Attribution License (CC BY). The use, distribution or reproduction in other forums is permitted, provided the original author(s) and the copyright owner(s) are credited and that the original publication in this journal is cited, in accordance with accepted academic practice. No use, distribution or reproduction is permitted which does not comply with these terms. 